\title{
Poorly Differentiated Follicular Thyroid Carcinoma with Rhabdoid Phenotype: A Clinicopathologic, Immunohistochemical and Electron Microscopic Study of Two Cases
}

Jorge Albores-Saavedra, M.D., Suash Sharma, M.D.

Division of Anatomic Pathology, The University of Texas Southwestern Medical Center, Dallas, Texas

Poorly differentiated thyroid carcinomas with follicular cell phenotype are not well defined. Different diagnostic criteria have been employed for these tumors, including solid growth, nodular, trabecular, and insular patterns. Cytologic features, such as a predominance of tall and columnar cells, have been considered to be diagnostic of poorly differentiated carcinoma. However, there is no agreement among surgical pathologists regarding morphologic criteria for poorly differentiated thyroid carcinoma. We report two unique thyroid neoplasms that we interpreted as poorly differentiated follicular carcinomas. Nodular, trabecular, and sheetlike patterns predominated in both tumors. They were composed of cells that were focally immunoreactive for thyroglobulin and had large vesicular nuclei with prominent nucleoli. A variable number of cells showed rhabdoid phenotype. The rhabdoid inclusions did not stain for thyroglobulin but contained whorls of intermediate filaments that were vimentin positive. There were foci of necrosis and numerous mitotic figures. Both patients were adults and died with multiple pulmonary metastases. The presence of rhabdoid cells in poorly differentiated follicular carcinomas broadens the spectrum of tumors with rhabdoid phenotype. More cases are needed to determine whether the rhabdoid phenotype is a marker for poorly differentiated follicular carcinoma as well as an independent adverse prognostic factor.

Copyright (C) 2001 by The United States and Canadian Academy of Pathology, Inc.

VOL. 14, NO. 2, P. 98, 2001 Printed in the U.S.A.

Date of acceptance: September 25, 2000.

Address reprint requests to: Dr. Jorge Albores-Saavedra, M.D., Director, Anatomic Pathology, UT-Southwestern Medical Center, 5323 Harry Hines Blvd., Dallas, TX 75390-9073; e-mail: albores.jorge@ pathology.swmed.edu; fax: 214-590-1411.
KEY WORDS: Immunohistochemistry, Poorly differentiated follicular carcinoma, Rhabdoid phenotype.

Mod Pathol 2001;14(2):98-104

Rhabdoid tumor was first described in 1978 as a distinctive, highly malignant, round-cell neoplasm of the kidney in children (1). Eight years later, extrarenal rhabdoid tumors were recognized (2). Subsequent studies established that many neoplasms of epithelial (3-5), endocrine (6), mesenchymal (7, $8)$, and melanocytic $(9,10)$ origin may have a rhabdoid phenotype. These extrarenal rhabdoid tumors arose in a wide variety of anatomic sites and affected both children and adults (11). It is now generally accepted that extrarenal rhabdoid tumors are not a distinct entity but rather are many different tumors with diverse cellular lineages. We report two cases of poorly differentiated follicular thyroid carcinomas with rhabdoid phenotype that behaved in an aggressive fashion. A discussion of the controversial concept of poorly differentiated carcinoma of the thyroid is included.

\section{MATERIALS AND METHODS}

The two cases of poorly differentiated follicular carcinomas with rhabdoid phenotype were retrieved from the personal consultation files of one of the authors (JAS). Multiple hematoxylin and eosin-stained sections were available for review in both cases. From the paraffin blocks, additional sections were obtained for immunohistochemical stains. Staining for cytokeratin (AE1/AE3, dilution 1:100; DAKO, Carpinteria, CA), epithelial membrane antigen (1:300; DAKO, Carpinteria, CA), thyroglobulin, (1:800; DAKO), calcitonin, (1:200; DAKO), vimentin, (1:200; DAKO), smooth-muscle actin (1:200; DAKO), muscle-specific actin (1:10; 
BioGenix, San Ramon, CA), and desmin (1:50, DAKO) was performed on a BioTek solutions TechMate 1000 automated immunostainer (BioTek Solutions, Inc, Santa Barbara, CA).

Fresh tumor tissue was available in one case. The tissue was fixed in $2 \%$ glutaraldehyde, postfixed in $1 \%$ osmium tetroxide, dehydrated, and embedded in Epon. The grids were examined with a JEOL 100SX electron microscope.

Clinical and follow-up information was obtained through the referring pathologists.

\section{Case 1}

A 42-year-old woman presented in 1986 with a mass in the left neck. On neck exploration, a $15 \times$ $15 \times 10-\mathrm{cm}$ mass was found replacing the entire left lobe of the thyroid and extending into the strap muscles, mediastinum, thymus, trachea, recurrent laryngeal nerves, and adjoining neck veins. Multiple cervical lymph nodes were enlarged. A left hemithyroidectomy was performed, but most of the tumor could not be removed. Serum calcitonin levels were found to be elevated both before (261 $\mathrm{pg} / \mathrm{mL})$ and after $(110 \mathrm{pg} / \mathrm{mL})$ surgery. Patient did well until August of 1988, when she developed a $6 \times$

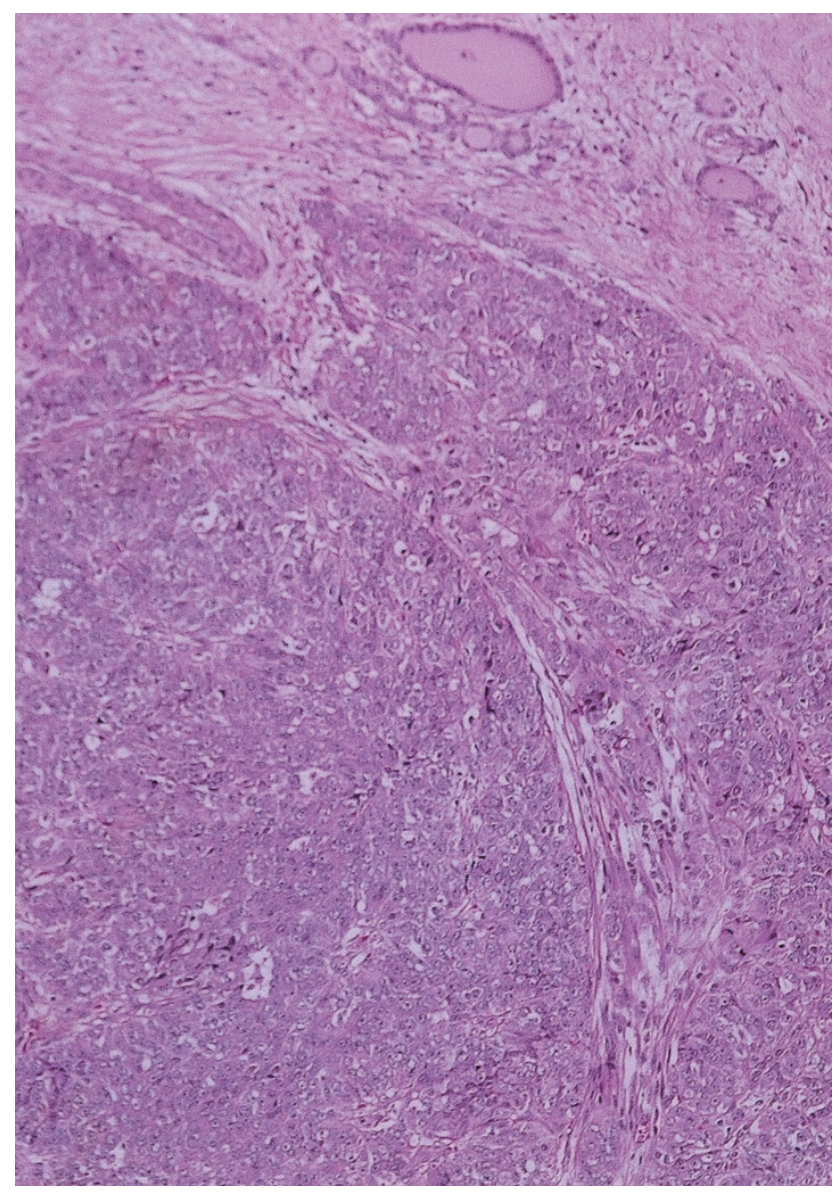

FIGURE 1. Case 1. The tumor displays nodular and trabecular patterns. A portion of normal thyroid is visible. 4-cm left supraclavicular mass, which on biopsy proved to be a metastatic tumor with similar histologic features as the thyroid mass. At the same time, enlarged nodes in the abdomen and retroperitoneum were evident by computed tomography scan. Chest x-ray showed multiple pulmonary metastases. The patient died 3 years after diagnosis. The excised tumor measured $8 \times 6 \mathrm{~cm}$, was gray-white, firm, and replaced $80 \%$ of the left thyroid lobe and isthmus. Extrathyroidal extension was obvious.

\section{Case 2}

A 58-year-old man presented in 1994 with a firm mass in the right thyroid lobe of 14 months' duration. The mass grew rapidly during the 3 months immediately before presentation. Fine-needle aspiration biopsy results of the mass were interpreted as a follicular neoplasm. A total thyroidectomy was performed. The patient developed bilateral pulmonary metastases 1 year after thyroidectomy. He was started on radioactive iodine 131 therapy but died 4 years later with multiple pulmonary metastases. On gross examination, the right thyroid lobe was totally replaced by a 6 -cm gray-white mass demonstrating

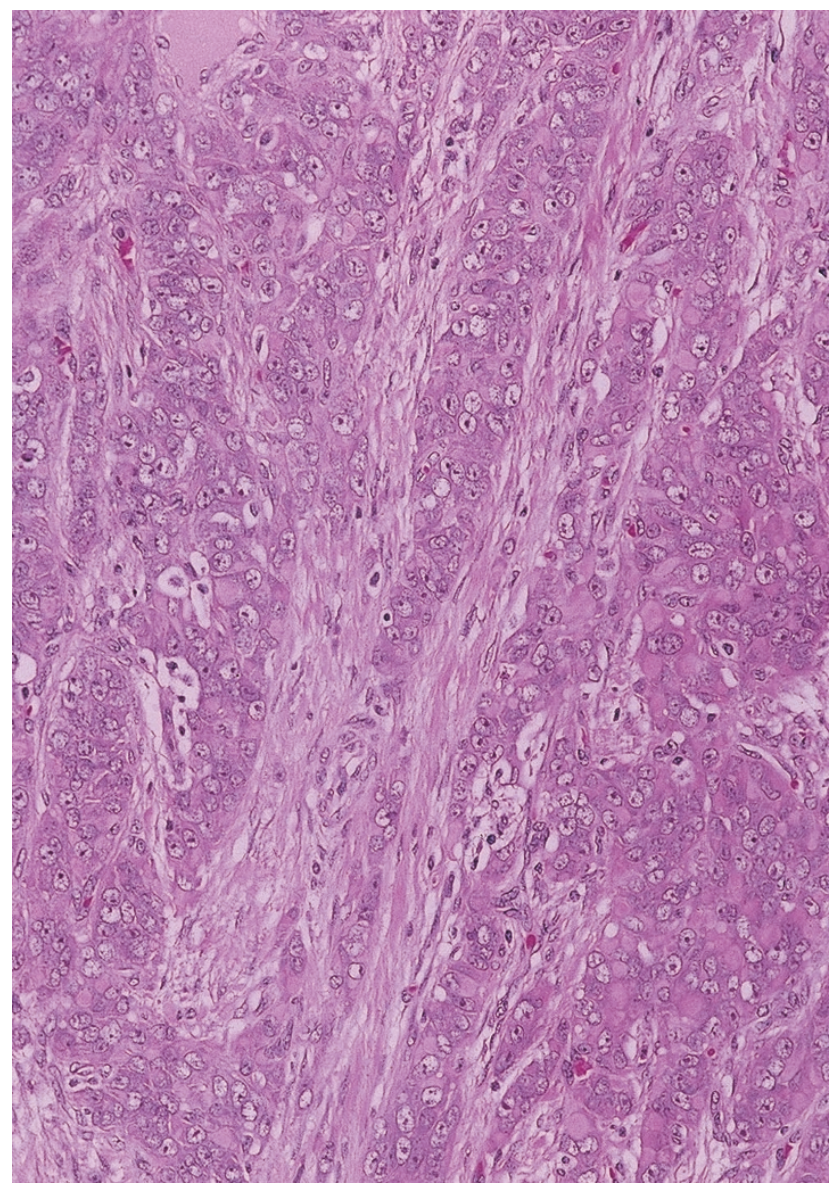

FIGURE 2. Case 1. Well defined trabecular structures are shown. Many of the cells contain eosinophilic inclusions. 


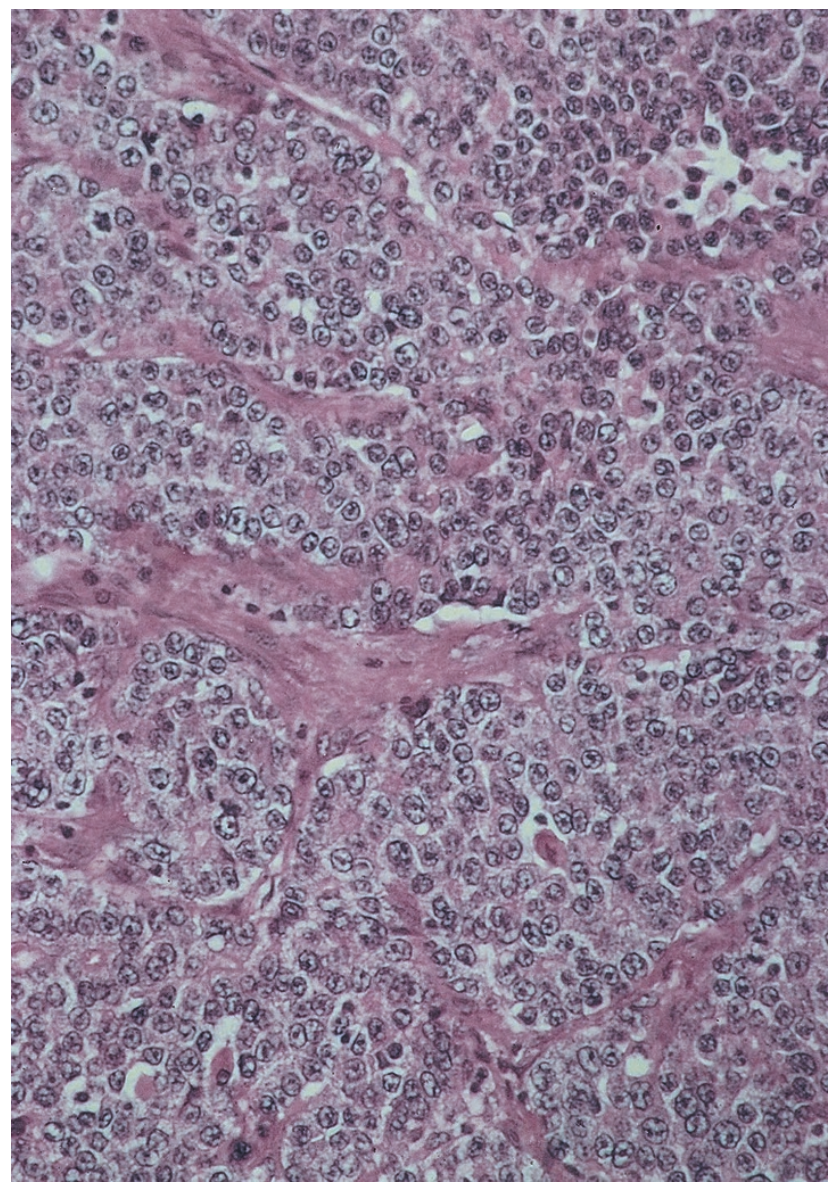

FIGURE 3. Case 2. Poorly defined trabeculae composed of cells with vesicular nuclei and prominent nucleoli.

focal extrathyroidal extension. The contralateral lobe showed no abnormalities.

\section{Microscopic and Ultrastructural Findings}

Both tumors were nonencapsulated, hypercellular, and had similar histologic features. The neoplastic cells were arranged in sheets, nodules, and trabeculae (Figs. 1-3). Microfollicles which had little or no colloid represented less than $5 \%$ of the tumors. The neoplastic cells had large vesicular nuclei with prominent nucleoli (Fig. 4). The cytoplasm was abundant and focally thyroglobulin positive. Approximately $30 \%$ of the cells from the first tumor and approximately $10 \%$ of the cells from the second tumor had eccentric eosinophilic inclusions characteristic of a rhabdoid phenotype (Fig. 5). The rhabdoid inclusions were vimentin positive but lacked immunoreactivity for cytokeratins, thyroglobulin, smooth-muscle actin, and desmin (Fig. 6). Both tumors contained foci of necrosis and numerous mitotic figures, including abnormal ones. The thyroid tissue adjacent to the tumor from Case 1 showed physiologic C-cell hyperplasia, defined as 50 normal-appearing, calcitonin-positive cells in at least one low-power field that were not recognized

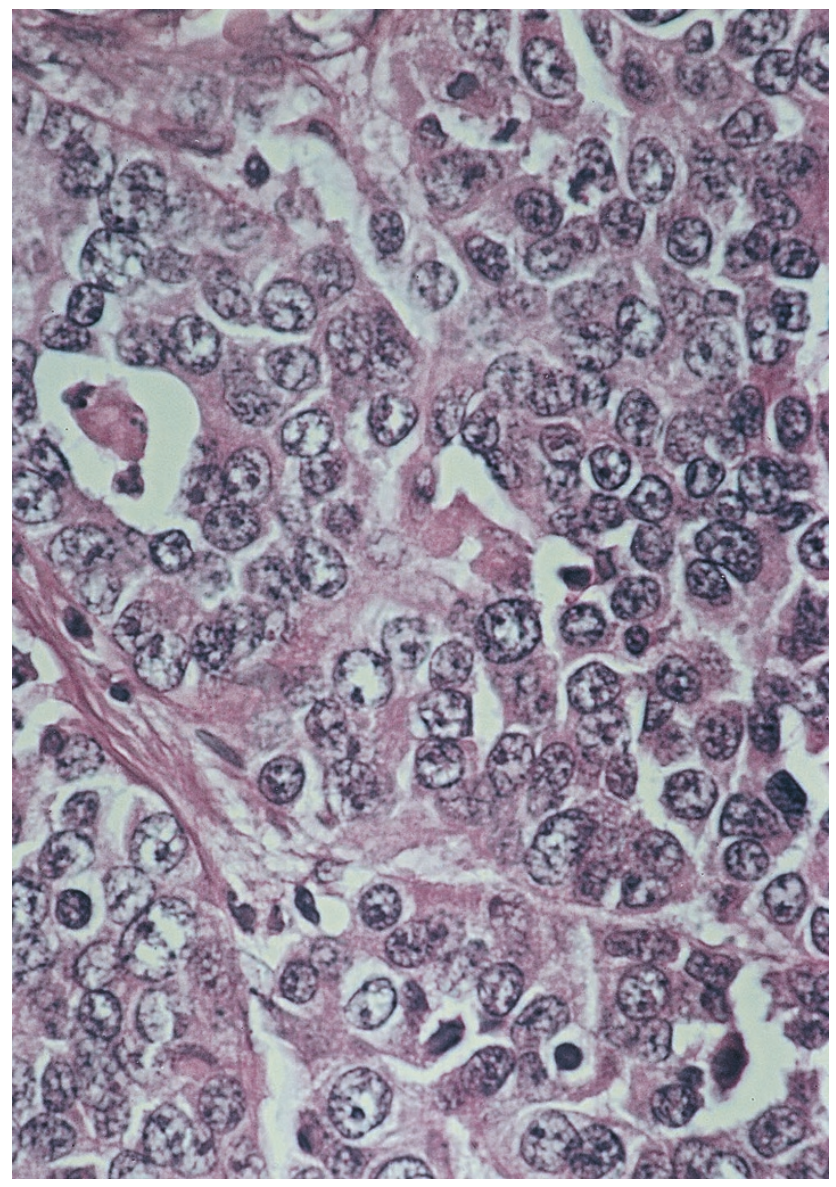

FIGURE 4. Case 2. A microfollicle is lined by cells with large vesicular nuclei and prominent nucleoli.

by conventional stains (12). Both tumors, however, were calcitonin negative. By electron microscopy, the eosinophilic inclusions were composed of whorls of intermediate filaments that displaced cytoplasmic organelles and the nuclei to the periphery (Figs. 7, 8).

\section{DISCUSSION}

A variety of thyroid carcinomas have been designated poorly differentiated. However, the concept of poorly differentiated thyroid carcinoma remains a source of controversy, perhaps because it often conveys a mixture of architectural cytologic and prognostic features (13). The term has been used for tumors with solid, trabecular, insular and/or scirrhous growth patterns (14-18). However, solid, trabecular, and insular growth patterns are seen in nonneoplastic lesions of the thyroid such as dyshormonogenic goiter, in follicular adenomas, and in thyroid tumors of low malignant potential (19). Solid and insular patterns are an integral component of radiation-induced pediatric papillary thyroid carcinomas, which are frequently associated with ret/PTC3 rearrangement and are regarded as 


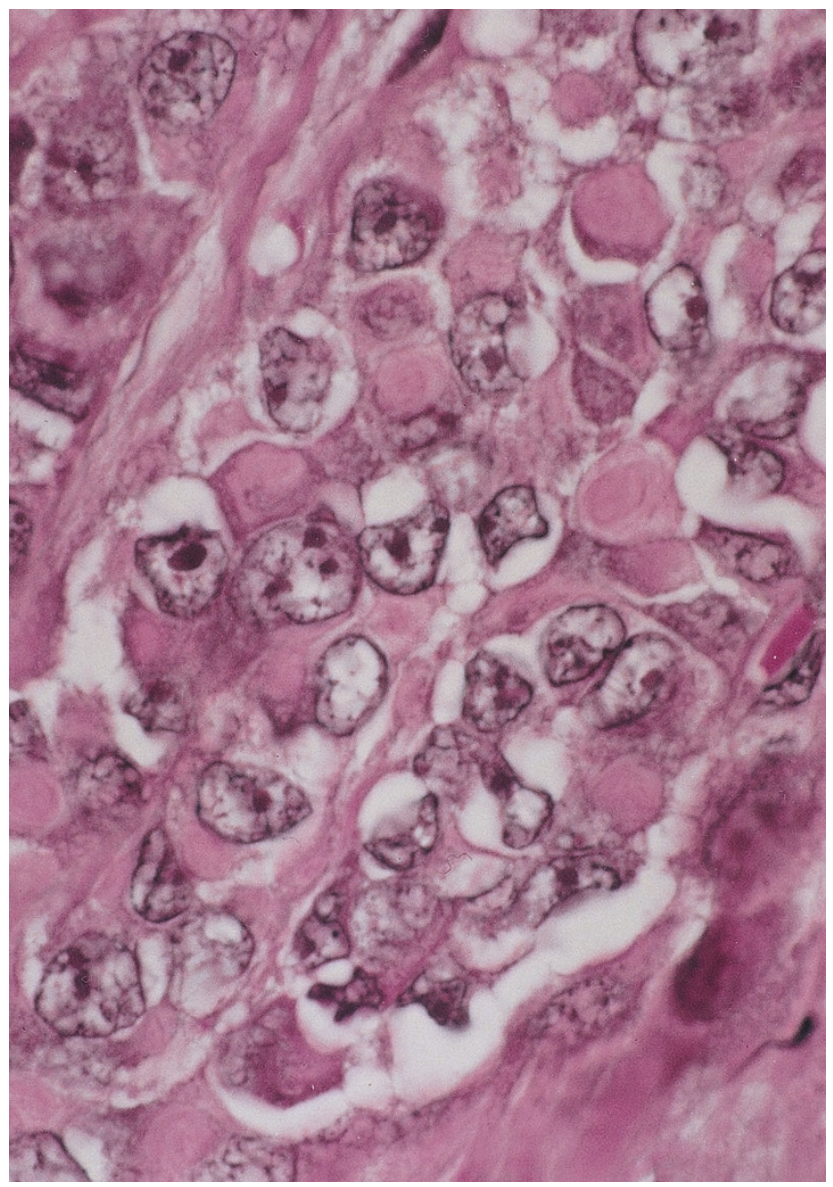

FIGURE 5. Case 2. Several eosinophilic inclusions are seen in the cytoplasm of neoplastic cells.

low-grade malignant tumors (20-22). Papillary and follicular carcinomas in adult patients may also show an insular growth pattern of variable extent $(23,24)$, but the cytologic features in the papillary, follicular, and insular patterns are usually similar or identical; therefore, the inclusion of this tumor type in the poorly differentiated category has been questioned (23). The insular pattern of some papillary carcinomas may contain cells with round hyperchromatic nuclei and coarsely granular chromatin similar to those of follicular carcinomas. These cells with "follicular"-type nuclei do not make the tumors poorly differentiated. Moreover, the insular and trabecular patterns may be a focal change in some papillary carcinomas and do not alter the excellent prognosis of these tumors (25). The cytologic atypia, mitotic figures, and even necrosis that often accompany these tumors with insular features have been observed in conventional papillary and follicular carcinomas and are considered independent prognostic factors $(13,26)$. Moreover, these carcinomas with insular pattern often show diffuse immunoreactivity for thyroglobulin, reflecting functional differentiation. Other investigators have emphasized cytologic features and include the

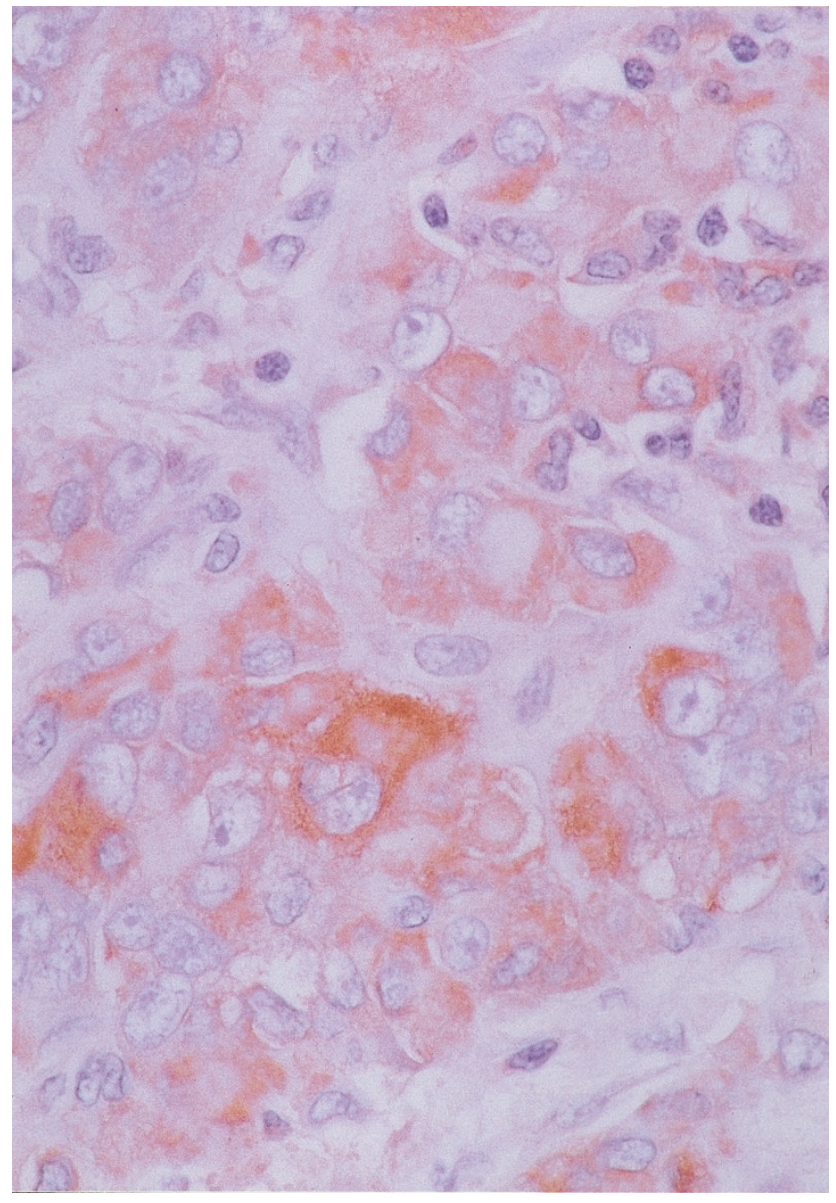

FIGURE 6. Case 1. The eosinophilic cytoplasmic rhabdoid inclusions are thyroglobulin negative, whereas the cells that lack inclusions are immunoreactive for thyroglobulin.

tall-cell variant of papillary thyroid carcinoma in the poorly differentiated category, perhaps because of its aggressive clinical course $(15,17)$. However, we believe that the height of the cell (tall cell) is not enough for this variant of papillary carcinoma to be considered poorly differentiated. Likewise, the columnar cell variant of papillary thyroid carcinoma has also been included in the group of poorly differentiated carcinoma and is regarded by some as a clinically aggressive neoplasm (27). We agree, however, with those that considered this unusual thyroid neoplasm a form of papillary carcinoma (2831) that when encapsulated or confined to the thyroid behaves as the conventional type of papillary thyroid carcinoma $(19,28)$. We agree with Akslen and LiVolsi (13) that the aggressive clinical course of some of these diverse thyroid neoplasms does not justify the designation of poorly differentiated carcinomas. In fact, the clinical course of thyroid carcinomas with follicular cell phenotype correlates better with tumor size, stage of disease, gender, age, extrathyroidal extension, and distant metastases than with histologic features $(32,33)$.

The two thyroid neoplasms reported here were composed of cells with large, round, vesicular nu- 


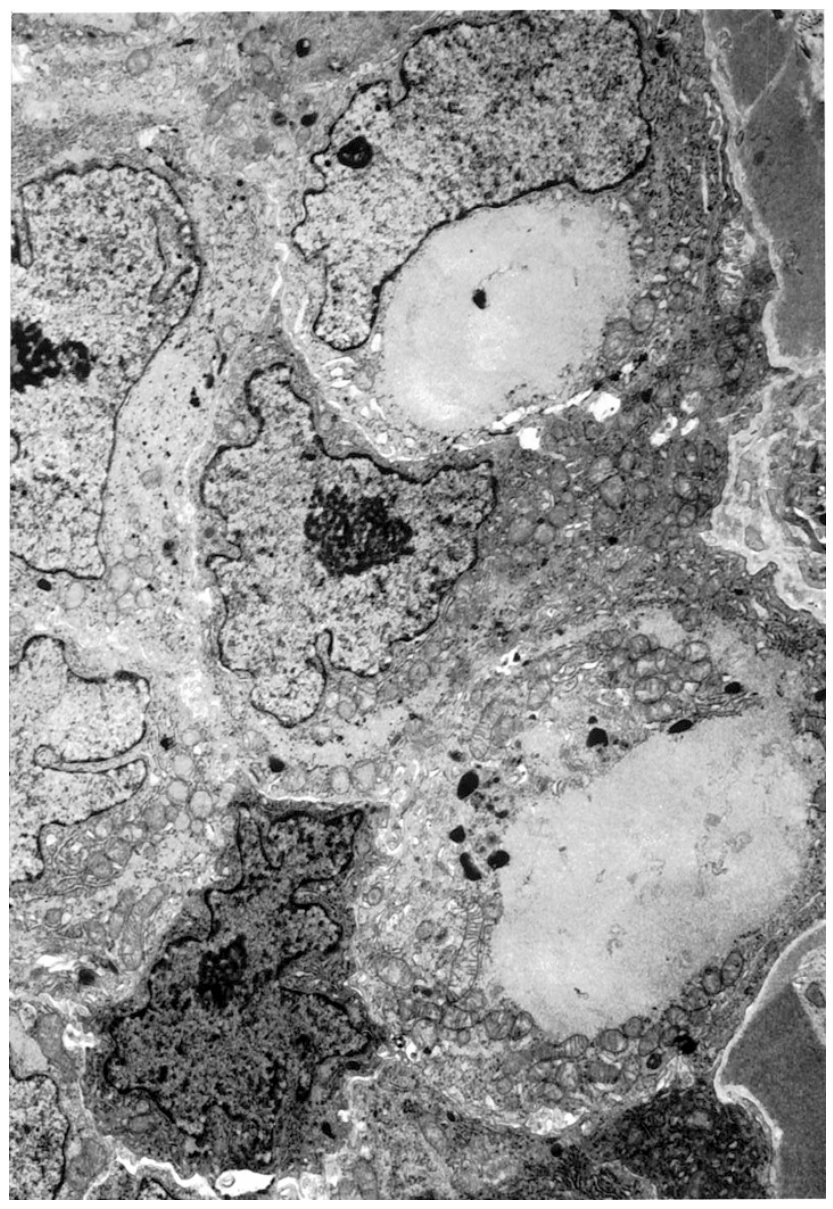

FIGURE 7. Electron micrograph depicting two cells with well-defined cytoplasmic inclusions that displace cytoplasmic organelles and the nucleus to the periphery.

clei; prominent nucleoli; and eosinophilic cytoplasm. These cells bear no resemblance to those of conventional papillary or follicular carcinoma. Moreover, many cells (30\%) in the first tumor and few cells $(10 \%)$ in the second tumor contained eosinophilic cytoplasmic inclusions composed of whorls of vimentin-positive intermediate filaments characteristic of the rhabdoid phenotype. The two neoplasms had foci of necrosis, contained very few follicles (less than $5 \%$ of the tumor), and exhibited predominantly sheetlike nodular and trabecular patterns. However, both tumors were focally immunoreactive for thyroglobulin, thus supporting their follicular cell phenotype. For all the reasons mentioned above, we have interpreted these two neoplasms as poorly differentiated follicular carcinomas. The two carcinomas were large, had extrathyroidal extension, and followed an aggressive clinical course. Both patients died with widespread metastatic disease; this occurred at 3 and 4 years after diagnosis.

The demonstration of rhabdoid phenotype in these poorly differentiated follicular carcinomas is not surprising because this feature is nonspecific

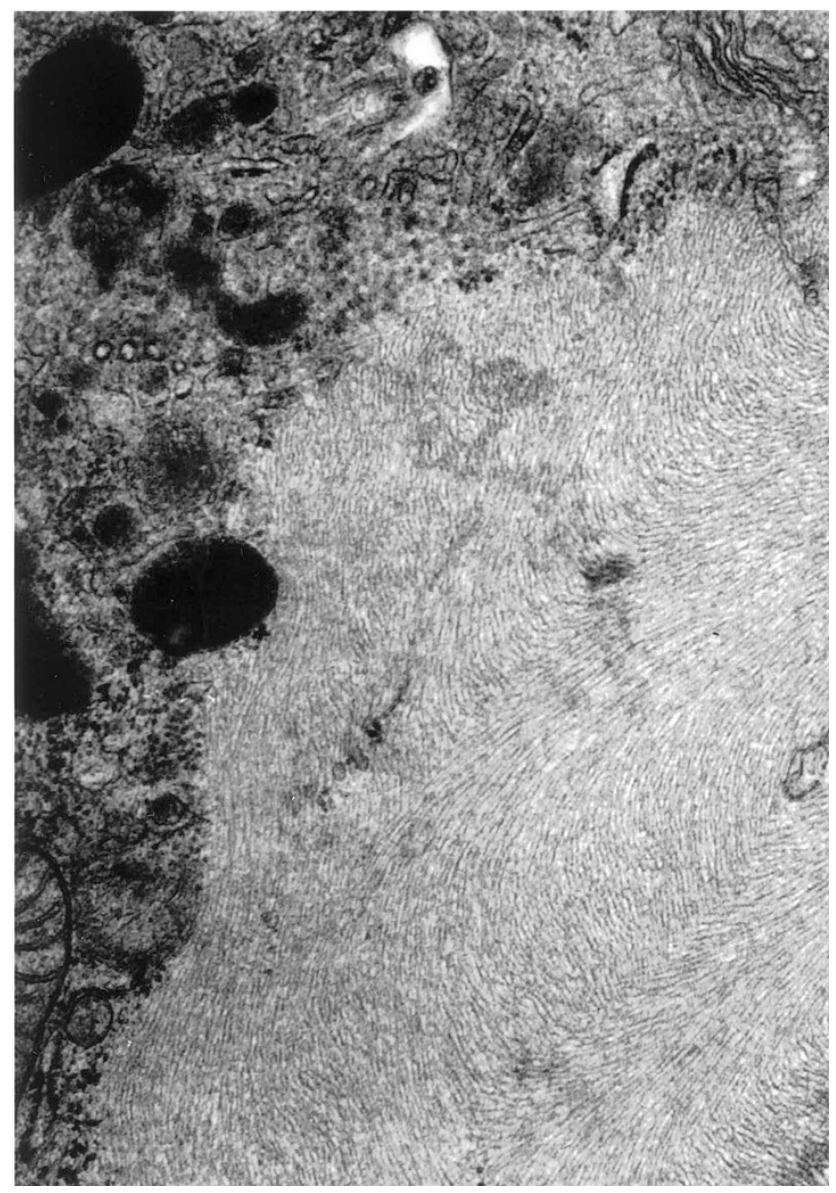

FIGURE 8. Higher magnification of one of the cytoplasmic inclusions depicted in Figure 7 showing detail of intermediate filaments.

and has been described in a wide variety of tumors such as melanomas, carcinomas, and various types of sarcomas $(7,11)$. Immunohistochemically, rhabdoid cells in extrarenal tumors have usually shown vimentin expression. Less frequently, they are immunoreactive to cytokeratin, epithelial membrane antigen, smooth-muscle actin, and desmin $(7,11)$. The two poorly differentiated follicular carcinomas reported here showed positivity for thyroglobulin. However, the rhabdoid cells were positive for vimentin and negative for thyroglobulin, cytokeratin, epithelial membrane antigen, smooth muscle actin, and desmin. These rhabdoid inclusions should be distinguished from cytoplasmic thyroglobulin inclusions that occur in follicular adenomas and carcinomas and reflect abnormal thyroglobulin secretion (12). They are easily separated from rhabdoid inclusions because they are more rounded and are periodic acid-Schiff, and alcian blue positive. By electron microscopy these inclusions correspond to a distended vesicle containing thyroglobulin (6).

The C-cell hyperplasia seen in thyroid tissue adjacent to the tumor from Case 1 explains the mild elevation of serum calcitonin levels in the patient. It has now been established that some thyroid tumors 
with follicular cell phenotype can be associated with physiologic C-cell hyperplasia that may give rise to hypercalcitoninemia $(12,34)$.

We first called attention to the existence of poorly differentiated follicular carcinomas with rhabdoid features in 1989 (35). In 1991, we included Case 1 in a study of cytoplasmic inclusions in thyroid neoplasms of follicular cell origin (6). Recently, three cases of well-differentiated follicular carcinoma with rhabdoid features were described (5). However, the illustrations suggest that the tumors are poorly differentiated follicular carcinomas, similar to our cases. These three cases occurred in women 43 to 56 years of age and behaved in an aggressive fashion: two patients died with metastases several months after diagnosis. In conclusion, four of the five cases of poorly differentiated follicular carcinoma with rhabdoid phenotype reported so far occurred in middle-aged women and followed an aggressive clinical course with death a few months to 4 years after diagnosis. However, more cases are needed to determine whether the rhabdoid phenotype is a marker for poorly differentiated follicular carcinoma and an independent prognostic factor.

\section{REFERENCES}

1. Beckwith JB, Palmer NF. Histopathology and prognosis of Wilm's tumor: results from the first National Wilm's Tumor Study. Cancer 1978;41:1937-48.

2. Sotelo-Avila C, Gonzalez-Crussi F, de Mello D, et al. Renal and extrarenal rhabdoid tumors in children: a clinicopathologic study of 14 patients. Semin Diagn Pathol 1986;3:15163.

3. Chetty R, Bhana B, Batitang S, Govender D. Lung carcinomas composed of rhabdoid cells. Eur J Surg Oncol 1997;23:432-4.

4. Chetty R, Bhathal PS. Caecal adenocarcinoma with rhabdoid phenotype: an immunohistochemical and ultrastructural analysis. Virchows Arch A Pathol Anat Histopathol 1993;422: 179-82.

5. Chetty R, Govender D. Follicular thyroid carcinoma with rhabdoid phenotype. Virchows Arch 1999;435:133-6.

6. Vardaman JC, Albores-Saavedra J. Cytoplasmic inclusions in thyroid neoplasms of follicular cell origin [abstract]. Am J Clin Pathol 1991;96:410.

7. Fanburg-Smith JC, Hengge M, Hengge UR, Smith JS, Miettenen M. Extrarenal rhabdoid tumors of soft tissue: a clinicopathologic and immunohistochemical study of 18 cases. Ann Diagn Pathol 1998;2:351-62.

8. Guillou L, Wadden C, Coindre JM, Krausz T, Fletcher CDM. "Proximal-type" epithelioid sarcoma, a distinctive aggressive neoplasm showing rhabdoid features. Clinicopathologic, immunohistochemical, and ultrastructural study of a series. Am J Surg Pathol 1997;21:130-46.

9. Borek BT, McKee PH, Freeman JA, Maguire B, Brander WL, Calonje E. Primary malignant melanoma with rhabdoid features: a histologic and immunohistochemical study of three cases. Am J Dermatopathol 1998;20:123-7.

10. Chang ES, Wick MR, Swanson PE, et al. Metastatic malignant melanoma with "rhabdoid" features. Am J Clin Pathol 1994; 102:426-31.

11. Wick MR, Ritter JH, Dehner LP. Malignant rhabdoid tumors: a clinicopathologic review and conceptual discussion. Semin Diagn Pathol 1995;12:233-48.
12. Albores-Saavedra J, Monforte H, Nadji M, Morales AR. C-cell hyperplasia in thyroid tissue adjacent to follicular cell tumors. Hum Pathol 1988;19:795-9.

13. Akslen LA, Li Volsi VA. Poorly differentiated thyroid carcinoma-it is important [letter]. Am J Surg Pathol 2000;24:310-3.

14. Carcangiu ML, Zampi G, Rosai J. Poorly differentiated ("insular”) thyroid carcinoma. A reinterpretation of Langhans' "wuchernde struma." Am J Surg Pathol 1984;8:655-68.

15. Nishida T, Katayama S, Tsujimoto M, Nakamura J, Matsuda H. Clinicopathological significance of poorly differentiated thyroid carcinoma. Am J Surg Pathol 1999;23:205-11.

16. Papotti M, Botta Micca B, Favero A, Palestini N, Bussolati G. Poorly differentiated thyroid carcinomas with primordial cell component. A group of aggressive lesions sharing insular, trabecular, and solid patterns. Am J Surg Pathol 1993;17: 291-301.

17. Pilotti S, Collini P, Manzari A, Marubini E, Rilke F. Poorly differentiated forms of papillary thyroid carcinoma: distinctive entities or morphologic patterns? Semin Diagn Pathol 1995;12:249-55.

18. Sakamoto A, Kasai N, Sugano H. Poorly differentiated carcinoma of the thyroid. A clinicopathologic entity for a highrisk group of papillary and follicular carcinomas. Cancer 1983;52:1849-55.

19. Wenig BM, Heffess CS. Reply. Thyroid papillary carcinoma of columnar cell type. A clinicopathologic study of 16 cases. Cancer 1998;83:2422-3.

20. Kitamura Y, Minobe K, Nakata T, et al. Ret/PTC3 is the most frequent form of gene rearrangement in papillary thyroid carcinomas in Japan. J Hum Genet 1999;44:96-102.

21. Klugbauer S, Demidchik EP, Lengfelder E, Rabes HM. Molecular analysis of new subtypes of ELE/RET rearrangements, their reciprocal transcripts and breakpoints in papillary thyroid carcinomas of children after Chernobyl. Oncogene 1998;16:671-5.

22. Nikiforov Y, Gnepp DR. Pediatric thyroid cancer after the Chernobyl disaster. Pathomorphologic study of 84 cases (1991-1992) from the Republic of Belarus. Cancer 1994;74: 748-66.

23. Ashfaq R, Vuitch F, Delgado R, Albores-Saavedra J. Papillary and follicular thyroid carcinomas with an insular component. Cancer 1994;73:416-23.

24. Sasaki A, Daa T, Kashima T, Yokoyama S, Nakayama I, Noguchi S. Insular component as a risk factor of thyroid carcinoma. Pathol Int 1996;46:939-46.

25. Albores-Saavedra J, Housini I, Vuitch F, Snyder WH 3rd. Macrofollicular variant of papillary thyroid carcinoma with minor insular component. Cancer 1997;80:1110-6.

26. Akslen LA, Li Volsi VA. Prognostic significance of histologic grading compared with subclassification of papillary thyroid carcinoma. Cancer 2000;88:1902-8.

27. Sobrinho-Simoes M, Nesland JM, Johannessen JV. Columnar-cell carcinoma. Another variant of poorly differentiated carcinoma of the thyroid. Am J Clin Pathol 1988;89: 264-7.

28. Evans HL. Encapsulated columnar cell neoplasms of the thyroid. A report of four cases suggesting a favorable prognosis. Am J Surg Pathol 1996;20:1205-11.

29. Ostrowski ML, Merino MJ. Tall cell variant of papillary thyroid carcinoma: a reassessment and immunohistochemical study with comparison to the usual type of papillary carcinoma of the thyroid. Am J Surg Pathol 1996;20:964-74.

30. Rosai J, Carcangiu ML, DeLellis RA. Tumors of the thyroid gland. Atlas of tumor pathology. Series 3. Fascicle 5. Washington, DC: AFIP; 1992.

31. Wenig BM, Thompson LD, Adair CF, Shmookler B, Heffess CS. Thyroid papillary carcinoma of columnar cell type: a clinicopathologic type of 16 cases. Cancer 1998;82:740-53. 
32. Akslen LA, Myking AO, Salvesen H, Varhaug JE. Prognostic importance of various clinicopathological features in papillary thyroid carcinoma. Eur J Cancer 1993;29A:44-51.

33. Hay ID, Bergstralh EJ, Goellner JR, Ebersold JR, Grant CS. Predicting outcome in papillary thyroid carcinoma: development of a reliable prognostic scoring system in a cohort of 1779 patients surgically treated at one institution during 1940 through 1989. Surgery 1993;114:1050-7.
34. Perry A, Molberg K, Albores-Saavedra J. Physiologic versus neoplastic C-cell hyperplasia of the thyroid: separation of distinct histologic and biologic entities. Cancer 1996;77: 750-6.

35. Albores-Saavedra J, Gould EW. Poorly differentiated follicular carcinoma with rhabdoid phenotype. Case 14. Tumors of thyroid-handout. Short Course \#7. International Academy of Pathology, 1989-1993. pp. 30-31.

\section{Book Review}

Shi S-R, Gu J, Taylor CR, editors: Antigen Retrieval Techniques: Immunohistochemistry and Molecular Morphology, 360 pp, Natick, MA, Eaton Book Publishing, 2000 (\$56.95).

No other technique in the past decade has revolutionized immunohistochemistry as has "antigen retrieval" (AR), a technique first described in a seminal paper by Shan-Rong Shi and colleagues in 1991. AR techniques have expanded tremendously the range of antibodies that can be employed in deparaffinized, formalin-fixed tissue, and have greatly expanded the range of applications as well as the tools with which they can be studied. This would appear to be a good time for a "state of the art" book on AR to appear: the technique is now widely accepted and relatively "mature," and enough papers have been published in the past decade describing its use that an attempt at organization and critical review is both useful and appropriate. And it would seem that no one is more qualified to produce a book on the subject than Shi and colleagues.

The book is organized in five major sections. An introductory historical overview by Jules Elias is followed by a "Basic Information" section, which includes chapters covering selected scientific background topics, including fixation and possible mechanisms of AR techniques, as well as a 10-page chapter on the various parameters (e.g., $\mathrm{pH}$, temperature, etc.) influencing the efficacy of AR techniques. The latter is such a key subject that I wish it had been expanded, with more corroborating tables and images. The middle sections of the book feature a number of chapters on applications of AR techniques, running the gamut from applications to specific an- tibodies (e.g., the MIB-1 anti-Ki67 antigen clone) to more exotic techniques such as immunoelectron microscopy, multiple immunolabeling techniques, combination antigen retrieval and tyramine amplification techniques, and celloidinembedded temporal bone specimens. The book concludes with a 25-page technical appendix.

The book gets off to a rocky start with an attack on alternative terminologies, particularly "heat induced epitope retrieval" (HIER), which is, the authors' comments notwithstanding, the most accurate nomenclature of the phenomenon. But overall this is a timely, comprehensive, and authoritative tome that fills an important need; it is a rare example of a work that actually benefits from being multiauthored (there are a total of 36 authors). There may be some overlap in chapters, but the different perspectives are both helpful and insightful. Although the black and white images within the text are a bit disappointing, there is a 12-page color insert in the middle of the book.

Although the general surgical pathologist might find the details of these chapters too arcane to be useful, diagnostic pathologists employing immunohistochemistry on a daily basis and struggling with optimizing antibody performance, and pathologists involved in research wishing to apply these techniques more broadly, will find this an invaluable guide. My copy is staying in the lab where it can be "dog-eared" and referred to daily.

\author{
Allen M. Gown \\ Phenopath Laboratories \\ Seattle, Washington
}

